\title{
Regimen Used to Treat Vulvar Cancer
}

National Cancer Institute

\section{Source}

National Cancer Institute. Regimen Used to Treat Vulvar Cancer. NCI Thesaurus. Code C159457.

Any regimen that can be used for the treatment of vulvar cancer. 